\title{
ТЕОРЕТИЧЕСКИЕ ПРЕДПОСЫЛКИ И ПРИНЦИПЫ ГИБКИХ МЕТОДОВ УПРАВЛЕНИЯ ПРОЕКТАМИ
}

\author{
V.P. Maslovsky, A.A. Ozerova
}

\section{THEORETICAL PREMISES AND THE PRINCIPLES OF FLEXIBLE METHODS OF PROJECTS MANAGEMENT}

Цель исследования - обобщение теоретических подходов к теории гибкого управления и ее практического применения. Задачи исследования: сформулировать определение Agile, определить суть методологии и основньх ее инструментов, рассмотреть опыт компаний, внедривших в свою деятельность гибкое проектное управление. Представлены результаты исследования основополагающих принципов гибких технологий, выявлены достоинства и недостатки Agile-технологий, а такюе описан опыт их внедрения в проектную деятельность. Полученные результаты позволяют сделать вывод, что методология Agile создана для достижения конкурентного преимущества компаниями за счет создания "работающего» продукта, способного удовлетворять потребности потребителя. Важно, что гибкие технологии прежде всего являются философией и требуют изменения проектной культуры внутри команды и бизнес-культуры всего предприятия. Эта культура становится инновационной, эмоционально и технологически вовлекающей сотрудников в производство качественного продукта, развивающей и поддерживающей командное и разделенное лидерство. Должна произойти смена парадигмы мышления: с привычки подчинения на привычку сотрудничества. Гибкое управление - это комплексный процесс разработки продукта, требующий использования итеращий (повторения определенных цииклов работы) с учетом постоянно изменяющцххся требований, которые должны быть реализованы за счет непрерывного взаимодействия с заинтересованными сторонами (клиентами, разработчиками, пользователями и др.). В общих чертах суть совокупности гибких методологий и соответствующих технологий заключается в важности внесения своевременных изменений в параметры проекта и в управление им по мере уточнений и конкретизаций требований заказчика. Таким образом, внедрение гибкого метода Agile возможно при следующих условиях: первое - от клиента требуется активное участие на протяжении всего проекта; второе - результат работы важнее, чем документация; третье - рабочая группа проекта составляет не более 7-9 человек; четвертое - участники осознают ответственность за результаты и действуют, обладая определенными правами на принятие решений; пятое - значение проекта четко обозначено; шестое общий объем работ по проекту возможно выполнять пошагово. 
Ключевъе слова: управление проектами, гибкое управление проектами, Agile-технологии, проект.

The research objective was the synthesis of theoretical approaches to the theory of flexible management and its practical application. The research problems were to formulate the definition of Agile, the essence of methodology and its main tools, to consider the experience of the companies which introduced flexible project management in the activity. The results of the research of fundamental principles of flexible technologies are presented, merits and demerits of Agile-technologies are revealed, and also the experience of their introduction in design activity is described. Received results allow drawing a conclusion that the methodology of Agile has been created for the achievement of competitive advantage by the companies due to the creation of the "working" product capable of satisfying the needs of the consumer. It is important that flexible technologies first of all are philosophy and demand the change of design culture in team and business culture of the whole enterprise. This culture becomes innovative, emotionally and technologically involving the employees in the creation of qualitative product developing and supporting the team and divided leadership. There has to be a change of the paradigm of thinking: from the submission habit on cooperation habit. Flexible management is complex process of the development of the product demanding using of iterations (repetition of certain cycles of work) taking into account constantly changing requirements which have to be realized due to continuous interaction with interested parties (clients, developers, users, etc.). In general the essence of set of flexible methodologies and appropriate technologies is in the importance of entering of timely changes into parameters of the project and in the management of it in the process of specifications and specifications of the customer's requirements. Thus, the introduction of flexible Agile method perhaps under following conditions: the first - from the client is required active participation throughout all project; the second - the result of the work is more important, than documentation; the third - working group of the project makes no more than 7-9 people; the fourth - the participants realize the responsibility for the results and act, having certain rights for decision-making; the fifth - the value of the project is accurately designated; the sixth - the total amount of works on the project is possible to be carried out step by step.

Keywords: management of projects, flexible management of projects, Agile-technologies, project.

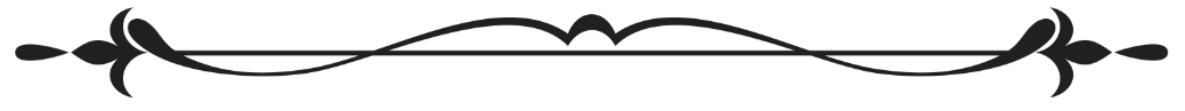


Введение. Современный рынок требует от бизнеса постоянных изменений, растут значимость персонализации продукта, власть потребителя и роль сервиса. Достижение стратегических, а зачастую и тактических целей компании невозможно без реализации проектов и, соответственно, применения методологии проектного менеджмента.

Проекты могут быть разными не только по масштабу, они также разделяются по сфере деятельности и степени инновационности. Не существует идеальной системы управления проектами, подходящей для каждого из видов проектов. Также не существует системы, которая бы подходила каждому руководителю и была удобна для всех членов команды. Однако за время существования проектного управления было создано немало эффективных подходов, методик и стандартов, которые можно взять на вооружение.

В настоящее время, в эпоху чрезвычайно изменчивой внешней среды, кризисов, нестабильной ситуации на рынках, высоких темпов технологического прогресса, традиционный подход перестал удовлетворять потребности бизнеса. Скорость реакции на события, которые происходят во внешней среде, должна быть молниеносной, поэтому в качестве альтернативы многие используют метод гибкого управления проектом - Agile.

Цели и задачи исследования состоят в обобщении теоретических подходов к теории гибкого управления и ее практического применения. Для достижения поставленной цели необходимо: сформулировать определение Agile, определить суть методологии и основных ее инструментов, рассмотреть опыт компаний, внедривших в свою деятельность гибкое проектное управление.

Результаты исследования и их обсуждение. Проектное управление в современном менеджменте является одним из наиболее эффективных инструментов, активно применяемых в различных сферах бизнеса: от тяжелой промышленности до интернет-маркетинга. Проект, имеющий в своей природе три базовых постулата: временная природа, уникальный характер и весомый фактор неопределенности, - предполагает использование особого инструментария, позволяющего эффективно управлять его составляющими частями и добиваться поставленных целей.

Традиционный проектный менеджмент, нашедший свое отражение в наиболее популярном стандарте РМВОК, в качестве базового методологического инструмента предполагает использование треугольника «качество-время-бюджет» [1]. Дженнер Стивен, член ассоциации управления проектами в Великобритании, в своей статье утверждает, что приблизительно 50-70 \% проектов и программ терпят неудачу [2]. Такая картина носит всеобщий характер и распространяется практически на все сферы экономики. В отчете Счетной палаты Великобритании (UK National Audit Office, NAO) отмечается, что «две трети проектов в го- 


\section{Социально-экономический и әуманитарный журнал Красноярского ГАУ. 2020. №1}

сударственном секторе завершаются с нарушением сроков, выходят за рамки бюджета и не приносят ожидаемых результатов», а также что в негосударственном секторе наблюдается такое же соотношение успешных и неудачных проектов. Б. Фливбьерг и другие отмечают: «По всему миру планируется и реализуется все больше инфраструктурных проектов, масштаб которых также возрастает, и в то же время становится понятно, что учет выполнения таких проектов поразительно неудовлетворителен» [3]. Проектный менеджмент требовал изменений: возросший фактор неопределенности и нестабильности окружающей среды совпал с активным экономическим ростом и технологическим прогрессом. Было невозможно решить проблему негибкости проектного управления разрастанием имеющейся методологии, базирующейся на устаревшей парадигме, - требовался кардинально другой подход.

Любой проект должен осуществлять некую миссию, связанную с созданием чего-то нового, уникального. В повседневной жизни, бизнесе и общественном взаимодействии создание ценности превращается в погоню за счастьем, самореализацией, достатком и так далее. Создание ценности через совершенствование также может происходить в рутинной производственной деятельности, где проектная активность (разработка новых продуктов, операционные изменения, изменения бизнеспроцессов) является процессом созданием ценности. Они направлены на удовлетворение потребностей клиента и при успешной реализации - на достижение большего благосостояния компании.

В феврале 2001 г. 17 независимыми практиками в области разработки программного обеспечения, входящих в Agile Alliance, был разработан и принят Agile Manifesto - манифест гибкого управления проектами [4]. «Скорость - Ценность - Эффективность» - три основных категории в этой парадигме. Теперь важны не сроки проекта сами по себе, а скорость, с которой будут создаваться и предоставляться для опробования заказчику ценные результаты, - сначала «минимально жизнеспособный продукт» (minimum viable product - MVP), а затем - конкурентоспособные версии или отдельные модули этого продукта, доработанные с учетом осмысленных заказчиком требований в ходе тестирования MVP. Продукт в рамках рассматриваемой парадигмы должен быть создан и доработан с минимальными или оптимальными для заказчика затратами и приемлемым уровнем риска.

Несмотря на то, что манифест касался в основном разработки программного обеспечения, закрепленные в нем ценности актуальны для использования гибких методов управления в любой сфере:

1) наивысшим приоритетом для нас является удовлетворение потребностей заказчика, благодаря регулярной и ранней поставке ценного программного обеспечения; 
2) изменение требований приветствуется даже на поздних стадиях разработки;

3) Agile-процессы позволяют использовать изменения для обеспечения заказчику конкурентного преимущества;

4) работающий продукт следует выпускать как можно чаще, с периодичностью от пары недель до пары месяцев;

5) на протяжении всего проекта разработчики и представители бизнеса должны ежедневно работать вместе;

6) над проектом должны работать мотивированные профессионалы. Чтобы работа была сделана, создайте условия, обеспечьте поддержку и полностью доверьтесь им;

7) непосредственное общение является наиболее практичным и эффективным способом обмена информацией как с самой командой, так и внутри команды;

8) работающий продукт - основной показатель прогресса;

9) инвесторы, разработчики и пользователи должны иметь возможность поддерживать постоянный ритм бесконечно;

10) постоянное внимание к техническому совершенству и качеству проектирования повышает гибкость проекта;

11) простота - искусство минимизации лишней работы - крайне необходима;

12) самые лучшие требования, архитектурные и технические решения рождаются у самоорганизующихся команд. Команда должна систематически анализировать возможные способы улучшения эффективности и соответственно корректировать стиль своей работы [4].

Впервые упоминание об Agile-технологиях, или гибких технологиях, стало появляться в IT сфере, где при разработке программного обеспечения создавался комплекс методов, способных заменить сложные и трудоемкие методы. В 1970 г. доктор Уинстон Ройс представил документ под названием «Управление развитием крупных программных систем» [5], в котором критиковалась последовательная разработка программного обеспечения. Он утверждал, что программа не должна разрабатываться по четко определенным фазам, как конвейер. Ройс рекомендовал использовать фазовый подход, в котором разработчики сначала собирают все требования проекта, далее завершают архитектуру и дизайн, затем записывают весь код и т. д. Идею совершенствования процесса разработки продукта в 90-х гг. поддержали Джим Хэнгсмит (главный разработчик метода «Адаптивной разработки», входящей в семейство Agile), Брайан Марик (консультант по разработке и тестированию программного обеспечения), Ари Ван Беннекум (разработчик, консультант, практикующий тренер).

По мнению М. Слайгер, гибкие методы - это набор последовательных действий, направленных на разработку продукта, ориентированных 


\section{Социально-экономический и әуманитарный журнал Красноярского ГАУ. 2020. №1}

на использование итеративного взаимодействия, динамическое формирование требований и обеспечение их реализации в результате постоянной работы внутри самоорганизующихся рабочих групп, состоящих из специалистов различного профиля [6].

Agile - это набор методов и методологий, которые помогают команде проекта эффективнее мыслить, работать и принимать решения. Эти методы и методологии охватывают все области управления проектами. Все методы и методологии состоят из процедур, максимально четких и оптимизированных, которые легко применить. Кроме того, Agile это мировоззрение, поскольку правильное мышление может оказать большое влияние на эффективность овладения процедурами [7].

Д. Приходько, говоря о гибких технологиях, отмечает, что данный подход противопоставляется традиционному управлению проектами, поскольку делает акцент на командной работе, гибкости и приветствию изменений, короткие и частые итерации в ходе ведения проекта [8].

Из представленных выше определений видно, что гибкие методы нацелены на командную работу. Команда проекта проводит встречи и совещания с заказчиками, на которых обсуждается результаты каждого цикла. Они включает в себя цели и задачи, а также ожидаемый результат, фиксируемый в документах. Гибкое управление подразумевает не полное документирование как в традиционных методах управления, а краткое описание решения возникшей проблемы или результат работы. После чего команда оценивает проделанную работу и расставляет приоритеты на следующий цикл [9].

Основную сущность гибких методов управления проектами можно представить в виде схемы, изображенной на рисунке 1.

Исходя из представленной схемы и предложенных выше определений, можно сказать, что гибкое управление - это комплексный процесс разработки продукта, требующий использования итераций (повторения определенных циклов работы) с учетом постоянно изменяющихся требований, которые должны быть реализованы за счет непрерывного взаимодействия с заинтересованными сторонами (клиентами, разработчиками, пользователями и другими стейкхолдерами).

В общих чертах суть совокупности гибкой методологии проектного управления заключается в важности внесения своевременных изменений в параметры проекта и в управление им по мере уточнений и конкретизаций требований заказчика.

Одним из основных инструментов Agile является методика Scrum $[10,11]$. На данный момент - это самый распространенный на практике инструментарий гибкой проектной разработки [12]. Представим основные элементы Scrum в таблице $1[13,14]$. 


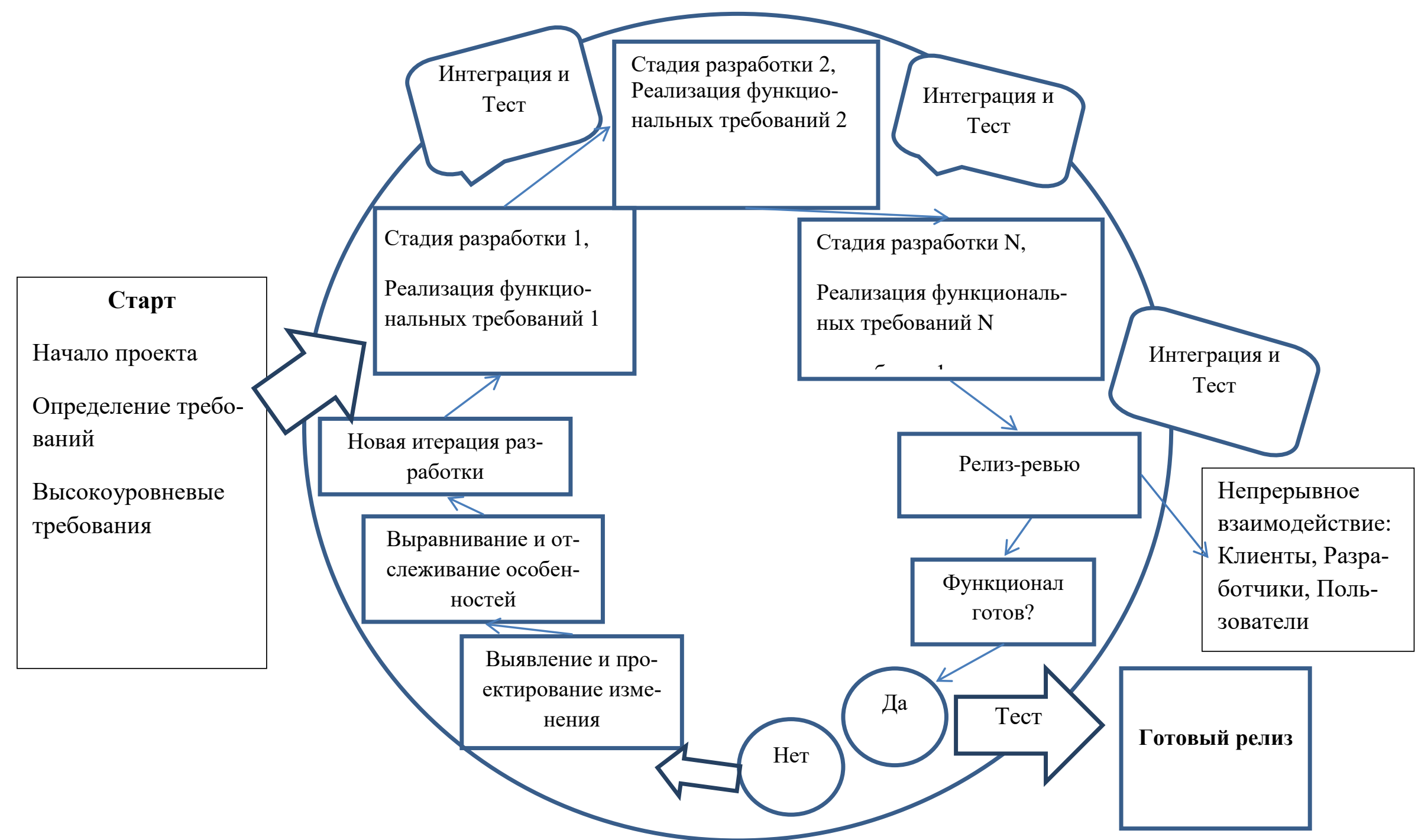

Рис. 1. Схема гибких методов управления 


\section{Основные элементы методологии Scrum}

\begin{tabular}{|l|l|}
\hline \multicolumn{1}{|c|}{ Элемент Scrum } & \multicolumn{1}{|c|}{ Описание } \\
\hline $\begin{array}{l}\text { Пользовательские } \\
\text { истории и бэклог }\end{array}$ & $\begin{array}{l}\text { Составляется набор «историй»- вариантов использования го- } \\
\text { тового продукта. Истории дробятся на задачи для реализации } \\
\text { и помещаются в отдельный список - бэклог продукта }\end{array}$ \\
\hline $\begin{array}{l}\text { Планирование } \\
\text { итерации }\end{array}$ & $\begin{array}{l}\text { Команда выбирает задачи из бэклога, которые она может } \\
\text { осуществить за один спринт (2-4 недели) }\end{array}$ \\
\hline Scrum-доска & $\begin{array}{l}\text { Доска с графами «Запланировано на спринт», «В Работе», } \\
\text { «Завершено» (и дополнительными), куда в открытом доступе } \\
\text { помещаются все задачи команды }\end{array}$ \\
\hline $\begin{array}{l}\text { Ежедневный } \\
\text { standuр }\end{array}$ & $\begin{array}{l}\text { Каждый день команда собирается на 10 минут возле доски за- } \\
\text { дач, обсуждая выполненные и запланированные задачи, } \\
\text { а также делясь возникшими проблемами }\end{array}$ \\
\hline Ретроспективы & $\begin{array}{l}\text { Собрания команды, где обсуждается ход выполненных работ } \\
\text { за несколько прошедших спринтов }\end{array}$ \\
\hline $\begin{array}{l}\text { Демонстрация } \\
\text { Мур }\end{array}$ & $\begin{array}{l}\text { Демонстрация полностью готовой к использованию функции } \\
\text { продукта в конце каждого спринта, получение обратной связи }\end{array}$ \\
\hline $\begin{array}{l}\text { Выделенный } \\
\text { владелец продукта } \\
\text { и sсrum-мастер }\end{array}$ & $\begin{array}{l}\text { В команде добавляются роли мсгит-мастера (следящего за ме- } \\
\text { тодологией) и владельца продукта (отвечающего за донесение } \\
\text { до команды мнения стейкхолдеров) }\end{array}$ \\
\hline $\begin{array}{l}\text { Диаграмма } \\
\text { выгорания }\end{array}$ & $\begin{array}{l}\text { В общем доступе имеется график, где отображается отноше- } \\
\text { ние выполненных задач по спринту к оставшимся }\end{array}$ \\
\hline
\end{tabular}

Основой Scrum является построение мультидисциплинарных самоорганизующихся небольших (оптимально: 7 человек) команд, которые планируют работу на короткий срок - спринт, итогом которого должен послужить некий продукт, готовый к демонстрации заказчику или другим заинтересованным лицам.

Роли в Agile-команде обычно представлены командой проекта, Scrum-мастером и владельцем продукта. Владелец продукта является связующим звеном между командой, заказчиком и окружением проекта. Его задача - максимальное увеличение ценности разрабатываемого продукта и повышение эффективности работы команды. Scrum-мастер ответственный за методологию scrum в команде. Задача Scrum-мастер помочь команде максимизировать ее эффективность посредством устранения препятствий, помощи, обучения и мотивации команде.

Также в Scrum важен бэклог - список тех или иных требуемых характеристик продукта, формируемый по ходу всей продолжительности работы над проектом. Команда выбирает ту или иную характеристику в соответствии с приоритетом и внедряет ее в продукт в течение одного спринта.

Основой Scrum является Sprint (спринт), в течение которого выполняется работа над продуктом. По окончанию Sprint должна быть получена новая рабочая версия продукта. Sprint всегда ограничен по времени (1-4 недели) и имеет одинаковую продолжительность на протяжении всей жизни проекта. 
Таким образом, «гибкий» подход к управлению проектами позволяет оставаться лояльным к изменениям, максимально упростить коммуникацию внутри команды, а также интегрировать заказчика в процесс работы над проектом, чтобы максимально достигать бизнес-ценностей $[11,13]$.

Несмотря на обозначенную специфику, Agile становится частью общепринятых стандартов проектного менеджмента $[15,16]$. Традиционные школы проектного менеджмента признают популярность и эффективность гибких методов проектного управления и включают их в свои стандарты, предлагая компаниям самостоятельно подобрать инструменты для решения своих задач. В 2015 г. в приложении к основному стандарту Британский институт AXELOS выпускает «PRINCE2 Agile» (AXELOS, 2015). В 2017 г. в новую шестую редакцию стандарта PMBOK включен Agile Practice Guide (PMI, 2017).

При этом любая методология имеет свои достоинства и недостатки. Достоинствами гибких технологий являются, прежде всего, их постоянная адаптация под окружающие изменения и требования заказчика и, исходя из этого, уменьшается число ошибок и дефектов в конечном результате, а короткие циклы разработки позволяют команде, менеджеру и заказчику видеть результат (рабочую версию продукта), что ускоряет выход продукта на рынок. Однако данные преимущества могут стать также и недостатками - постоянная обратная связь, необходимость адаптировать под изменяющиеся условия проекта документацию и обязательное присутствие и контроль со стороны заказчика могут затягивать сроки проекта. Если команда проекта кросс-функциональная, то есть каждая итерация проходит в разных местах, то общее планирование и ведение проекта становится затруднительным. Кроме того, команда проекта должна обладать определенными знаниями и опытом, чтобы в моменте предлагать и анализировать возможные способы улучшения эффективности собственной работы, быть самоорганизованной и клиентоориентированной. Далеко не всегда ресурсы проекта позволяют привлечь таких специалистов. Помимо этого, к плавающему значению стоимости проекта приводит сложность подсчета итоговой суммы работы (дробные, короткие циклы, постоянное усовершенствование продукта).

Перечислим далее критерии, обуславливающие возможность применения Agile в том или ином проекте [13].

Неопределенность конечного результата и относительная «жесткость» содержания проекта. В отличие от проекта строительства здания, где финальный результат проекта и требования к нему становятся понятными на этапе проектирования, - все дальнейшие шаги лишь позволяют реализовать планируемый результат - в IT проектах требования могут сводиться к приблизительному набору требуемых функций программного продукта. Интерфейс программы и итоговый функционал может меняться по ходу проекта в зависимости от сложившихся условий (появление новых технологий, появление новых конкурентов, запросы будущих потребителей и т. д.). 


\section{Социально-экономический и әуманитарный журнал Красноярского ГАУ. 2020. №1}

Преобладающая доля стоимости человеческих ресурсов в структуре стоимости проекта. В традиционном инвестиционном проекте преобладающую долю затрат обычно составляют расходы на материалы, строительство, оборудование и другие материальные ресурсы. В IT-проектах же стоимость складывается в первую очередь из стоимости труда программистов и других участников команды. Остальные затраты: содержание рабочего места, эксплуатация техники и программное обеспечение, - составляют меньшую долю в структуре затрат.

Высокая динамика изменений внешней среды. IT - наиболее динамично развивающаяся сфера. Запаздывание с выходом продукта на несколько месяцев может стать фатальным. Жизненный цикл продуктов чрезвычайно короток, а для поддержания жизнеспособности продукта требуются постоянные совершенствования и дополнения (обновления программы, новые версии продукта, новые функции в старых продуктах или же совершенно новые версии продуктов).

Команда, работающая над проектом, продолжает свою работу над продуктом после сдачи в формате поддержки и доработки продукта. Потребность в постоянной поддержке и доработке продукта после его «сдачи» требует участия команды программистов на этапе эксплуатации результатов проекта. Привлечение новой другой команды нецелесообразно, так как затраты на «погружение» в уже готовый программный продукт будут чрезвычайно высоки. Иногда участие команды сводится к устранению мелких проблем, возникших при эксплуатации; в других случаях - команда работает на полную мощность, продолжая развивать текущий программный продукт.

Возможен поэтапный (модульный) запуск и ранний выход на рынок. Программное обеспечение электронной книги в первую очередь должно позволять воспроизводить файлы электронных книг. Функция подключения к онлайн-каталогу, доступ к офисным программам и калькулятор можно добавить позднее, когда основной функционал будет опробован пользователями и протестирован. Работа над программным обеспечением позволяет привносить пользователю новый функционал «по облаку», посредством обновлений.

Выполненный анализ говорит о том, что Agile как инструмент повышения ценности проекта (его конкурентоспособности, скорости выхода на рынок и готовности к изменениям) может быть использован не во всех проектах или же не в каждой из стадий проекта. Стоит отметить, что не всем подразделениям и сферам подходит Agile. Так, для обычных операций (техническое обслуживание, закупки или финансовый учет) технологии Agile почти не применимы. Гибким командам больше всего подходит работа с инновационными проектами. Применяя новые подходы, они улучшают качество самого продукта и бизнес-процессов. А ес- 
ли связанные команды будут работать по разным методологиям либо использовать Agile в тех сферах, где лучше применять традиционные методы, то это может привести к краху всей системы, поэтому очень важно построить оптимальную организационную структуру, четко выстроить этапы разработки продукта.

Следует также учитывать и особенности инструментария гибких технологий. Например, по исследованиям AgileRussia [17], в разработке программных продуктов чаще используют Scrum, в финансовых компаниях чаще используют Канбан, а иногда встречается и использование сразу двух инструментов. Это обусловлено тем, что скорость изменений в IT значительно выше, чем в финансах, вследствие чего предпочтителен Scrum как подход, позволяющий за счет быстрых экспериментов гибко управлять приоритетами и менять направление в зависимости от изменений внешней среды и условий «на входе». Современный подход, совмещающий Scrum и Lean, SixSigma, идеально подходит для мобильной разработки - вначале он реализует постановку рабочего процесса по Scrum, а затем применяет подходы Lean, SixSigma для статистического управления качеством [18].

Можно выделить три основных подхода к организации работы над проектом: традиционный проектный менеджмент, гибкое управление проектами и гибридная модель. В работах $[13,14]$ предлагается модель, позволяющая отнести проект к той или иной форме управления проектами (рис. 2).

В правой части схемы представлены критерии «гибких» проектов на основе критериев, сформированных нами ранее. Слева - характеристики наименее гибких проектов, относящихся, например, к инженерным сооружениям с высоким уровнем регламентации и низкой толерантностью к изменениям. Между данными полярностями представлена условная шкала, где позиция справа соответствует совершенно «гибкому» проекту, позиция слева - наименее «гибкому». Все промежуточные состояния относят проект к гибридным моделям, где будет уместно применение комбинации из нескольких методик.

В работах $[12,19-21]$ приводятся практические свидетельства применения гибких подходов в различных областях: IT, телекоммуникациях, банках и даже строительстве [15], где спринты превращаются в еженедельные планы, пользовательские истории - в наборы работ, демонстрации заказчику - в инспекцию площадки, график выгорания задач в S-кривую расходования бюджета и времени. Подобный гибридный подход позволяет команде фокусироваться на ценности, следовать изменениям, при этом используя привычные инструменты управления временем, стоимостью и характеристиками проекта. 


\section{Социально-экономический и әуманитарный журнал Красноярского ГАУ. 2020. №1}

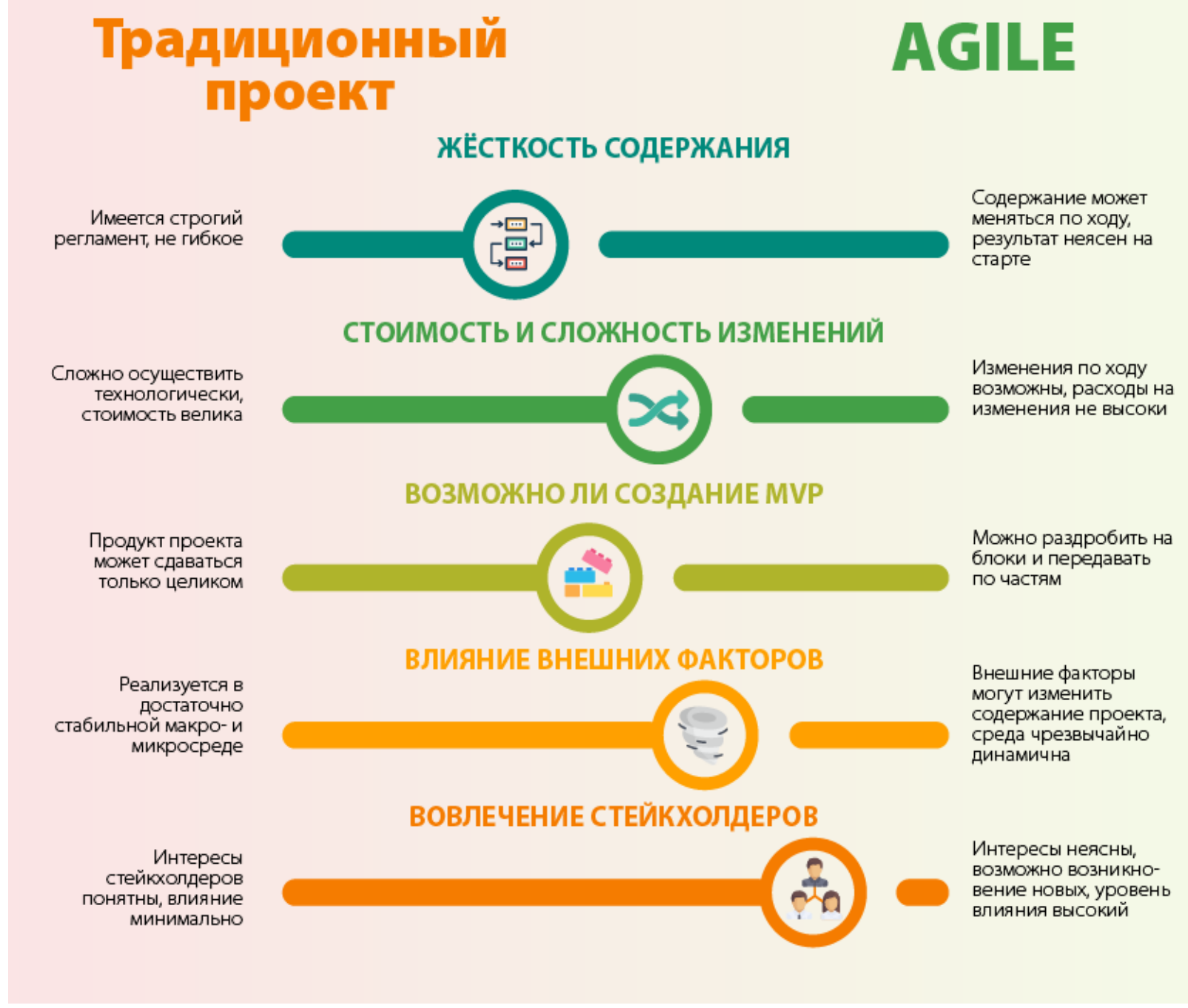

Рис. 2. Модель определения «аибкости» проекта

Несмотря на кажущуюся сложность, как в зарубежных, так и в отечественных компаниях используют гибкое управление в своих бизнеспроцессах, добиваясь высоких результатов. Это не только IT- компании, такие как Google или Amazon, но и компании, которые предоставляют другие услуги, например Сбербанк. Изначально Сбербанк не был компанией, функционирующей по принципам Agile, однако современная философия управления проектами подразумевает внедрение новых адаптивных технологий.

Внедрили гибкое управление компания-оператор таргетированных email-рассылок Return Path, которая использует гибкие технологии, в частности методологию Kanban, для отбора кандидатов на должности в компании. Kanban-доски стали использоваться для распределения нагрузки между сотрудниками таким образом, чтобы с кандидатом могли коммуницировать наиболее оперативно те сотрудники, у которых в данный момент есть такая возможность. 
Также в число компаний, внедривших гибкое проектное управление, входят следующие представители бизнеса:

- новостная некоммерческая организация National Public Radio использует методы Agile для разработки программной сетки вещания;

- компания John Deere использует их для разработки новых машин;

- шведская компания Saab - для производства новых самолетовистребителей;

- лидер в облачных технологиях резервного копирования Intronis использует их для маркетинга;

- глобальный провайдер логистических услуг $3 \mathrm{PL}-$ C.H. Robinson применяет их в сфере управления персоналом;

- Mission Bell Winery использует их везде - от производства вина до складирования, а также в работе команды высшего руководства.

Успешная реализация любого проекта в современных условиях невозможна без постоянного ориентирования команды на ценность, создаваемую в ходе выполнения проекта.

Процедура максимального учета запросов потребителя через его интеграцию в процесс работы над проектом, реализуемая в рамках гибкой или гибридной методологии, по нашему мнению, наиболее точно отвечает этой парадигме.

\section{Выводы}

1. Традиционная модель управления проектами, основанная на «водопадном» методе планирования, не всегда и не в полной мере может учесть изменения, происходящие в сфере окружения проекта.

2. Гибкие методы управления Agile зародились и развивались в сфере IT. Анализ этой методологии свидетельствует, что Agile как инструмент повышения ценности проекта, его конкурентоспособности, скорости выхода на рынок и готовности к изменениям может быть использован не во всех проектах.

3. Методология Agile становится частью общепринятых стандартов проектного менеджмента, а практика его применения свидетельствует об эффективности этого метода.

4. Если требуется создание по-настоящему уникального продукта, который должен своими характеристиками удовлетворить множество заинтересованных сторон, причем используемые при производстве технологии можно отнести к инновационным - принципы Agile позволят более гибко подойти к процессу работы над проектом. В случае же, когда проект реализуется в более или менее стабильном окружении, а технологии производства понятны и отработаны, гибкие методы управления могут лишь внести хаос и усложнить работу над проектом.

5. Сочетание традиционных и гибких методов проектного менеджмента путем создания «гибридных» моделей позволяет использовать преимущества каждого из них и частично уменьшить присущие им недостатки. 


\section{Социально-экономический и әуманитарный \\ журнал Красноярского ГАУ. 2020. №1}

\section{Литература}

1. Руководство к Своду знаний по управлению проектами (Руководство РМВОК). 5-е изд. М., 2013. 589 с.

2. Дженнер $C$. Почему проекты терпят неудачу и как с этим бороться? Доводы в пользу упорядоченного, быстрого и экономичного принятия решений. Ч. 1 // Управление проектами и программами. 2015. № 3. С. $76-89$.

3. Фливбъорг Б., Брузелиус Н., Ротенгатmер В. Мегапроекты и риски: анатомия амбиций. М.: Альпина Паблишер, 2016. 288 с.

4. Agile manifesto. URL: https://www.agilealliance.org.

5. Poŭc У. Управление развитием крупных программных систем // URL: https: // www.savkinks.ru.

6. Слайгер M. Переход менеджера проекта на гибкую разработку // Addison-Wesley Professional. 2018. № 10. C. 31-36.

7. Стеллман Э. Постигая Agile. - URL: https://fictionbook.ru/author/ djennifer_grin/postigaya_agile/read_online.html.

8. Приходъко Д.И. Организационные структуры успешных корпораций. М.: Инфотропик Медиа, 2018.

9. Johnson J., Boucher D.K., Connors K., Robinson J. Collaborating on Project Success // Software Magazine. 2017. № 3. P. 7-11.

10. Стандарты управления проектами // ГК «Проектная практика». URL: https://pmpractice.ru.

11. The Scrum Guide. The definitive Guide to Scrum: The Rules of the Game by Ken Schwaber, Jeff Sutherland. URL: https://www.scrum guides.org/docs/scrumguide/v1/scrum-guide-us.pdf.

12. URL: https://scrumtrek.ru/blog/11-j-ezhegodnyj-otchet-state-of-agile.

13. Локтионов Д.А., Масловский В.П. Критерии применения Agileметодологии для управления проектом // Креативная экономика. 2018. Т. 12, № 6.

14. Масловский В.П., Локтионов Д.А. Механизмы создания и управления ценностью проекта // Актуальные психолого-педагогические, философские, экономические и юридические проблемы современного российского общества: коллективная монография. Ульяновск: Зебра, 2018. С. 193-265.

15. Agile and Lean Applied to Construction by A. Smith. URL: http://ennova.com.au/blog/2011/o9/agile-lean-compared-applied-co nstruction.

16. Agile Ways on "Projectified" by Lauri Bingham. URL: https://www.pmi.org/learning/training-development/projectified-pod cast/agile-journey.

17. Отчет об исследовании Agile в России в 2017 году. URL: https://scrumtrek.ru/userfiles/reports/AgileSurvey17.pdf.

18. Все дело в Agile-2: особенности внедрения гибкой разработки. URL: https://habr.com/ru/company/mailru/blog/431898. 
19. Масловский В.П., Локтионов Д.А. Управление ценностью проекта в маркетинговом агентстве // Экономика и предпринимательство. 2017. № 12, ч. 2. C. 1134-1144.

20. Wick A. Can You Develop Standards That Embrace Both Agile And Traditional Approaches? 2015 - URL: https://www.batimes. com/angelawick/can-you-develop-standards-that-embrace-both-agile-andtraditional-approaches.html.

21. Bingham L. Agile Ways on "Projectified", PMI. URL: https://www.pmi.org/learning/training-development/projectified-pod cast/agile-journey.

\section{Literatura}

1. Rukovodstvo k Svodu znanij po upravleniyu proektami (Rukovo-dstvo PMBOK). 5-e izd. M., 2013. 589 s.

2. Dzhenner $S$. Pochemu proekty terpyat neudachu i kak s etim borot'sya? Dovody v pol'zu uporyadochennogo, bystrogo i ekonomichnogo prinyatiya reshenij. CH. 1 // Upravlenie proektami i programmami. 2015. № 3. S. 76-89.

3. Flivb'org B., Bruzelius N., Rotengatter $V$. Megaproekty i riski: anatomiya ambicij. M.: Al'pina Pablisher, 2016. 288 s.

4. Agile manifesto. URL: https://www.agilealliance.org.

5. Rojs $U$. Upravlenie razvitiem krupnyh programmnyh sistem // URL: https: // www.savkinks.ru.

6. Slajger $M$. Perekhod menedzhera proekta na gibkuyu razrabotku // Addison-Wesley Professional. 2018. № 10. S. 31-36.

7. Stellman E. Postigaya Agile. - URL: https://fictionbook.ru/author/ djennifer_grin/postigaya_agile/read_online.html.

8. Prihod'ko D.I. Organizacionnye struktury uspeshnyh korpora-cij. M.: Infotropik Media, 2018.

9. Johnson J., Boucher D.K., Connors K., Robinson J. Collaborating on Project Success // Software Magazine. 2017. № 3. R. 7-11.

10. Standarty upravleniya proektami // GK «Proektnaya praktika». URL: https://pmpractice.ru.

11. The Scrum Guide. The definitive Guide to Scrum: The Rules of the Game by Ken Schwaber, Jeff Sutherland. URL: https://www.scrum guides.org/docs/scrumguide/v1/scrum-guide-us.pdf.

12. URL: https://scrumtrek.ru/blog/11-j-ezhegodnyj-otchet-state-of-agile.

13. Loktionov D.A., Maslovskij V.P. Kriterii primeneniya Agile-metodologii dlya upravleniya proektom // Kreativnaya ekonomika. 2018. T. 12, № 6.

14. Maslovskij V.P., Loktionov D.A. Mekhanizmy sozdaniya i uprav-leniya cennost'yu proekta // Aktual'nye psihologo-pedagogicheskie, filosofskie, ekonomicheskie i yuridicheskie problemy sovremennogo rossijskogo obshchestva: kollektivnaya monografiya. Ul'yanovsk: Zebra, 2018. S. 193265 . 
15. Agile and Lean Applied to Construction by A. Smith. URL: http://ennova.com.au/blog/2011/o9/agile-lean-compared-applied-co nstruction.

16. Agile Ways on "Projectified" by Lauri Bingham. URL: https://www.pmi.org/learning/training-development/projectified-pod cast/agile-journey.

17. Otchet ob issledovanii Agile v Rossii v 2017 godu. URL: https://scrumtrek.ru/userfiles/reports/AgileSurvey17.pdf.

18. Vse delo $v$ Agile-2: osobennosti vnedreniya gibkoj razrabotki. - URL: https://habr.com/ru/company/mailru/blog/431898.

19. Maslovskij V.P., Loktionov D.A. Upravlenie cennost'yu proekta v marketingovom agentstve // Ekonomika i predprinimatel'stvo. 2017. № 12, ch. 2. S. 1134-1144.

20. Wick A. Can You Develop Standards That Embrace Both Agile And Traditional Approaches? 2015 - URL: https://www.batimes. com/angelawick/can-you-develop-standards-that-embrace-both-agile-andtraditional-approaches.html.

21. Bingham L. Agile Ways on "Projectified", PMI. URL: https://www.pmi.org/learning/training-development/projectified-pod cast/agile-journey.

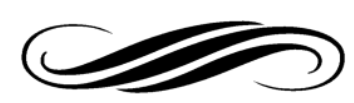

